\section{Doctors claim A-bomb tests linked to rise in child leukaemia deaths}

\section{David Dickson reports on a statistical survey in Southern Utah}

RESEARCH workers at the University of Utah claim to have discovered a twoand-a-half fold increase in the leukaemia death rate among children exposed to fall-out from atomic bomb tests carried out in the Nevada desert in the 1950s.

In one of the first systematic studies of civilians exposed to fall-out from the tests, the research workers have found a particularly large increase in the number of leukaemia deaths in children born around 1951-the beginning of the testing period-and that leukaemia death rates returned to their previous levels after the testing was stopped in the early 1960 s.

The results of the study have already been passed to federal officials in Washington in a series of meetings last month, but have not yet been published. And although the research workers are cautious about interpreting a correlation as indicating a causal relationship the results of the study will provide a major boost to over 100 cancer patients and relatives of those who have died from cancer in areas surrounding the test site, who are currently suing the US government for a total of $\$ 232$ million in damages.

"This is the bombshell that is going to establish beyond doubt that these claims are on solid ground," $\mathrm{Mr}$ Stewart Udalla, a former Secretary of the Interior, who is now in private law practice and is pressing the case against the government, said last week.

Residents of Southern Utah have for years suspected that an apparently abnormal level in the number of cancers in the area was linked to fallout from the A-bomb tests. The two towns of Parowan and Paragonah, for example, with a combined population of 1,800 , experienced four cases of leukaemia from 1956 to 1967 , two to three times the expected rate.

So far, however, evidence has remained sketchy and largely anecdotal, with insufficient data to establish any significant correlation. Two weeks ago, for example, it was learned that a study carried out in 1965 by a scientist with the US Public Health Service's Division of Radiological Health, who claimed to have shown an excessive level of leukaemia among residents of two Utah counties exposed to fall-out, was ignored and subsequently forgotten.

Interest in a possible correlation between the tests and civilian deaths was revived last year, when evidence was presented to a congressional sub- committee that an excessive incidence of leukaemia had occurred among soldiers who took part in exercises while the tests were underway (a claim which has recently been substantiated by the Center for Disease Control).

Such evidence prompted the University of Utah's research team, headed by Dr Joseph L. Lyon, of the Department of Family and Community Medicine in the College of Medicine, to carry out a detailed study of child deaths in the state between 1944 and 1975. The results of their study are about to be published in The New England Journal of Medicine.

Dr Lyon and his colleagues focused their attention on children under 15 who died in 17 counties in the south of the state, which experienced relatively high fall-out from 26 tests between 1951 and 1958. Radioactive debris from the tests was carried eastwards by the wind from the Nevada test site into Utah.

The children were divided into two groups for comparison: a "high exposure" group, who died 1951-58; and a "low exposure" group who died before 1951 or were born after 1958 .

Analysis of the death certificates showed the leukaemia mortality rate among children in the low exposure group in these counties to be about half that in the remainder of the state, and indeed the rest of the US - a fact which is unexplained, but may be related to the ascetic life-style of the Mormon communities which predominate in the area.

In the high exposure group, however, although leukaemia mortality started off equally low, it climbed through the 1950s to reach a peak slightly higher than the US average in the early 1960 s, subsequently falling back towards its previous level. This group did not reveal any excess for other childhood cancers.

The greatest excess in leukaemia deaths occurred in the 10-14 age group, where the number of deaths rose from between one and two per 100,000 to almost 10 per 100,000 around 1961-implying a particularly high incidence of leukaemia among those born towards the beginning of the testing period, with the disease causing death 10 to 14 years later. there was a slightly lesser elevation in the 5-9 age group-those who were born around 1956-and little excess among the 0-4 age group. Furthermore the standard mortality ratio for the
The research workers found that

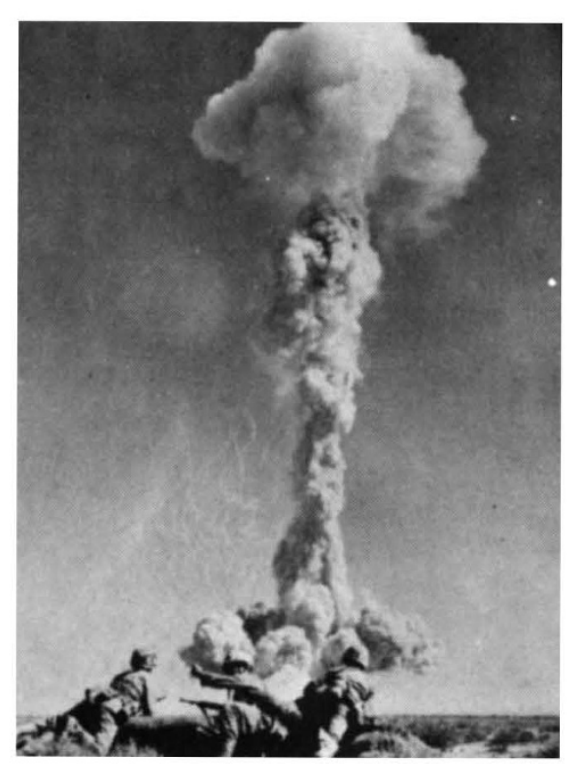

Nevada bomb test, 1952, watched by US marines

two groups for the whole age range was slightly higher for boys than for girls.

Even the children who lived in counties which had not experienced the high fall-out rates showed a slight increase in leukaemia mortality. But over half the excess deaths (16 out of 30) occurred in those counties which had been subject to the heaviest fallout, even though these containd only $10 \%$ of the population.

Dr Lyon and his colleagues are being cautious about their results. They do not claim to have demonstrated that the excess leukaemia deaths were in fact due to the bomb tests, merely that there is a statistical correlation between the two. Their evidence is already being studied by other statisticians.

However, enough data has been produced by the study to convince others that when the Atomic Energy Commission told Utah residents in the early 1950 s that the fall-out they were receiving was, to quote public statements, "far from hazardous" and presented "no danger" it was being grossly misleading-even admitting that the statements may have reflected the state of knowledge at the time.

Prompted by results such as those contained in the new study, President Carter has directed $\mathrm{Mr}$ Joseph Califano, Secretary of the Department of Health, Education and Welfare, to reevaluate the findings of all earlier studies of the incidence of leukaemia in Utah, particularly in the south-west.

DHEW is expected to name the University of Utah researchers as the principal investigator in a major follow-up study But whatever emerges, it may be too late to prevent what $\mathrm{Mr}$ Udall has called the "terrible tragedy" that took place 20 years ago. 